\title{
Synthesis, characterization and thermal properties of inorganic-organic hybrid
}

\author{
Z.L. Da, Q. Q. Zhang, D. M. Wu, D. Y. Yang, F. X. Qiu* \\ School of Chemistry and Chemical Engineering, Jiangsu University, Zhenjiang 212013, China
}

Received 7 July 2007; accepted in revised form 20 August 2007

\begin{abstract}
Poly (St-MAn-APTES)/silica hybrid materials were successfully prepared from styrene (St), maleic anhydride (MAn) and tetraethoxysilane (TEOS) in the presence of a coupling agent 3-aminopropyltriethoxysilane (APTES), by freeradical solution polymerization and in situ sol-gel process. The TEOS content varied from 0 to 25 wt $\%$. Fourier transform infrared spectroscopy and ${ }^{29} \mathrm{Si}$ nuclear magnetic resonance spectroscopy were used to characterize the structure of the hybrids (condensed siloxane bonds designated as $\mathrm{Q}^{1}, \mathrm{Q}^{2}, \mathrm{Q}^{3}, \mathrm{Q}^{4}$, with 3-aminopropyltriethoxysilane having mono-, di-, tri, tetra-substituted siloxane bonds designated as $\mathrm{T}^{1}, \mathrm{~T}^{2}$ and $\mathrm{T}^{3}$ ). The results revealed that $\mathrm{Q}^{3}, \mathrm{Q}^{4}$ and $\mathrm{T}^{3}$ were the major microstructure elements in forming a network structure. The hybrid materials were also characterized by the methods of solvent extraction, Transmission Electron Microscopy (TEM), differential scanning calorimetry (DSC) and thermogravimetric analysis (TGA) for determining the gel contents, particle size and thermal performance. The results showed that gel contents in the hybrid materials were much higher, the $\mathrm{SiO}_{2}$ phase were well dispersed in the polymer matrix, silicon dioxide existed at nanoscale in the composites, which had excellent thermal stability.
\end{abstract}

Keywords: polymer composites, organic-inorganic hybrid material, sol-gel process

\section{Introduction}

Over the past decade, the synthesis and characterization of inorganic-organic hybrid materials by the sol-gel process have received considerable attention. This is mainly due to the mild conditions, such as low temperature and pressure[1-3]. In addition, the sol-gel process is a convenient method for preparing oxide films from alkoxysilyl group containing materials via continuous reaction steps of hydrolysis and condensation. This technology has been a great achievement in making ceramic or organic modified hybrid materials in the past two decades, by which homogeneous materials with higher thermal stability, density, and hardness can be produced. These hybrid materials posses organic and inorganic properties [4] which can also be tuned through changing the functionality or seg-

*Corresponding author, e-mail: fxqiuchem@163.com

(c) BME-PT and GTE ment size of each component, tayloring thermal, mechanical, electronic, optical and optoelectronic properties. Common applications of the hybrid materials as passive or active layer in optoelectronic devices have been reported, including protective coating [5], contact lenses [6], high refractive index films [7], thin film transistors [8], solar cells [9], light-emitting diodes [10], optical waveguides materials [11] and photo chromic materials [12]. These properties are associated with $\sigma$ conjugation [13]. Many researchers have demonstrated that monolithic, transparent hybrid materials without macroscopic phase separation can be prepared by properly controlling the conditions of hydrolysis and condensation of sol-gel materials such as tetraethoxysilane (TEOS) or tetramethoxysilane (TMOS) [14-16]. Organic and inorganic constituents can be chemically bonded or just physi- 

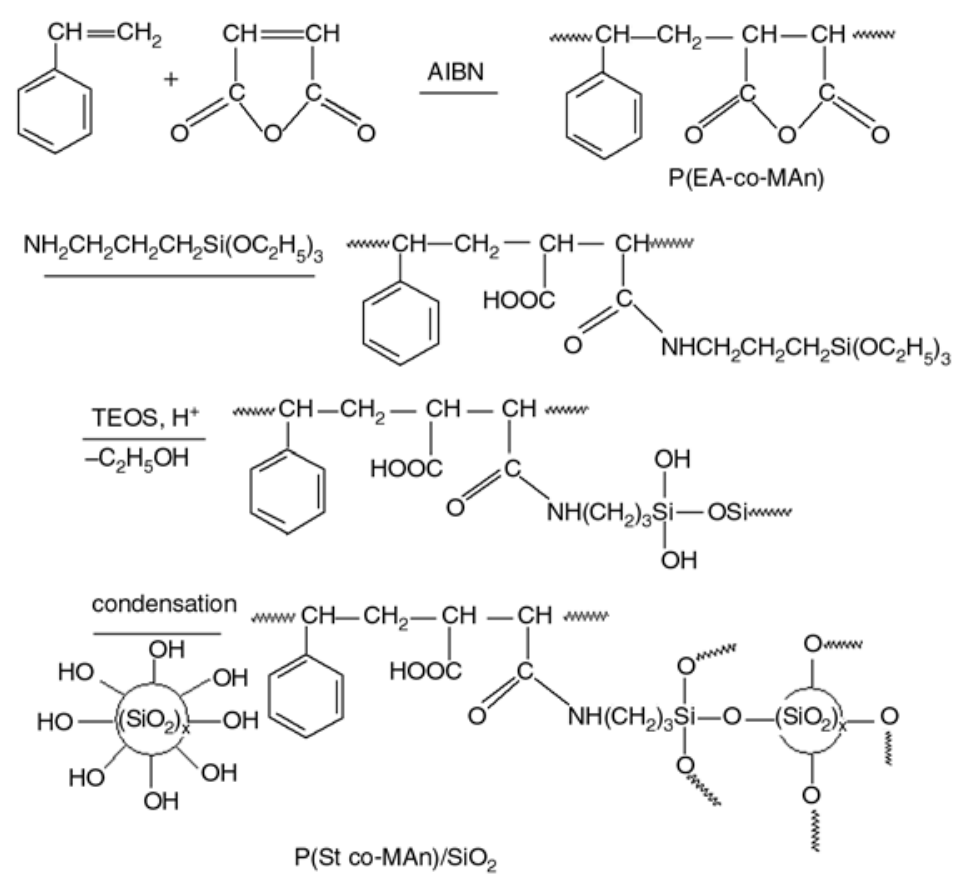

Figure 1. Preparation of organic-inorganic hybrid by sol-gel process

cally mixed in these hybrid materials. A significant feature to enhance the compatibility in the hybrid material, however, is the formation of covalent bonding between organic polymers and inorganic components.

In this study, copolymer was prepared by free radical copolymerization of styrene (St) with maleic anhydride (MAn). Copolymer precursor holding trimethoxysily-functionality was prepared by 3-aminopropyltriethoxysilane (APTES), coupling of the copolymer with miscible TEOS as an inorganic silica matrix for a sol-gel process. Then the copolymer precursor was hydrolyzed and condensed in the presence of an aqueous $\mathrm{HCl}$ catalyst to generate poly (St-MAn-APTES)- $\mathrm{SiO}_{2}$ hybrid material as shown in Figure 1.

\section{Experimental}

\subsection{Materials}

Styrene (St), maleic anhydride (MAn), 2,2'-azobisisobutyronitrile(AIBN) and TEOS were purchased from Shanghai Chemical Reagent Company. Initiating agent AIBN was purified by recrystalization from alcohol and then dried in a vacuum oven. APTES was purchased from Nanjing Shuguang Chemical Plant. Tetrahydrofuran (THF) was purified by distillation and other reagents, solvents were obtained commercially and were used as received.

\subsection{Preparation of hybrid $P$ (St-MAn-APTES)/SiO ${ }_{2}$}

Hybrid was prepared according to the scheme, as shown in Table 1. St and MAn were taken in a $500 \mathrm{ml}$ three-neck round-bottomed flask. The THF and initiator AIBN were added under nitrogen purging. The reaction temperature was maintained at $70^{\circ} \mathrm{C}$ for $3 \mathrm{~h}$ and the copolymerization was carried out. Then APTES was added under nitrogen and stirred for $2 \mathrm{~h}$ at $70^{\circ} \mathrm{C}$. The copolymer precursor for preparing the hybrid films was obtained. Then the TEOS homogeneous hydrolysate, prepared using deionized water, hydrochloric acid and THF, were added into the copolymer precursor solution. Meanwhile the sol-gel process was carried

Table 1. Monomer compositions for preparingไhybrid thin films

\begin{tabular}{|c|c|c|c|c|}
\hline Sample & St [g] & MAn [g] & APTES [g] & TEOS [wt \%] \\
\hline Z1 & 28.61 & 26.96 & 40.53 & 5 \\
\hline Z2 & 27.11 & 25.54 & 38.40 & 10 \\
\hline Z3 & 25.39 & 24.31 & 36.26 & 15 \\
\hline Z4 & 24.09 & 22.70 & 34.13 & 20 \\
\hline Z5 & 22.59 & 21.28 & 32.00 & 25 \\
\hline
\end{tabular}

All of polymerization mixtures had the following fixed composition: $[\mathrm{APTES}] /[\mathrm{St}]+[\mathrm{MAn}]+[\mathrm{APTES}]=25 \mathrm{~mol} \%$;

$[\mathrm{AIBN}] /[\mathrm{St}]+[\mathrm{MAn}]+[\mathrm{APTES}]=3.25 \mathrm{~mol} \%$ 
out. The synthetic route is shown in Figure 1. The homogeneous transparent sol can be obtained and then transferred to a conical flask. Solvents have been evaporated off the resulting gel slowly for 5 days and then was dried at $110^{\circ} \mathrm{C}$ under vacuum for $5 \mathrm{~h}$ to remove residual solvent and by-products (water and alcohol etc.). The thermally stable solgel hybrid material was obtained.

\subsection{Measurement}

FT-IR spectra of the prepared thin films were obtained on $\mathrm{KBr}$ pellets using Nicolet AVATAR 360 spectrometer. ${ }^{29} \mathrm{Si}$ NMR was performed using a Bruker DPX-400WB, Germany. HITACHI H-600 Transmission Electron Microscope (TEM) measured the particle sizes. Transmission electron microscopy (TEM) micrographs were obtained using a Hitachi H-600 operated at $80 \mathrm{kV}$ with a 35 micron objective. Thermogravimetric analysis (TGA) and differential scanning calorimetry (DSC) were performed on NETZSCH STA 449C. The programmed heating range was from room temperature to $800^{\circ} \mathrm{C}$, at a heating rate of $10^{\circ} \mathrm{C} / \mathrm{min}$ under nitrogen atmosphere. The measurement was taken using 6-10 mg samples. TGA and DSC curves were recorded. The determination of sol fraction was to put the obtained hybrid materials in the sorbite extraction set and use acetone circulation reflux for $36 \mathrm{~h}$. Then dried to constant weight in the vacuum drying oven. Sol fraction is calculated by Equation (1):

$A=\frac{m_{1}-m_{2}}{m_{1}} \cdot 100 \%$

where $A$ is the sol fraction, $m_{1}$ and $m_{2}$ are the mass before and after extraction, respectively.

\section{Results and discussion}

\subsection{Fourier transforms infrared spectra}

The results of FT-IR spectra $\left(4000-400 \mathrm{~cm}^{-1}\right)$ of hybrid materials Z1-Z5 are shown in Figure 2. It could be easily found that 1788 and $1850 \mathrm{~cm}^{-1}$ was attributed to stretching peaks of carbonyl in carboxylic $(-\mathrm{COOH})$ groups. Transmissions at 1732 and $1700 \mathrm{~cm}^{-1}$ belonged to stretching peaks of carbonyl in amid (-CONH) groups. Therefore it could be confirmed that amino-group of coupling agent APTES broke maleic anhydride of copolymer to

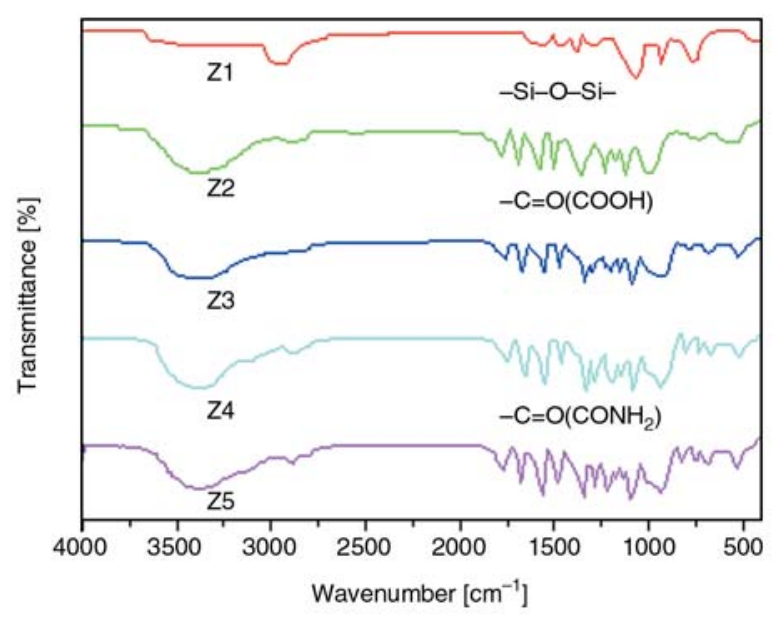

Figure 2. FT-IR spectra of hybrid materials

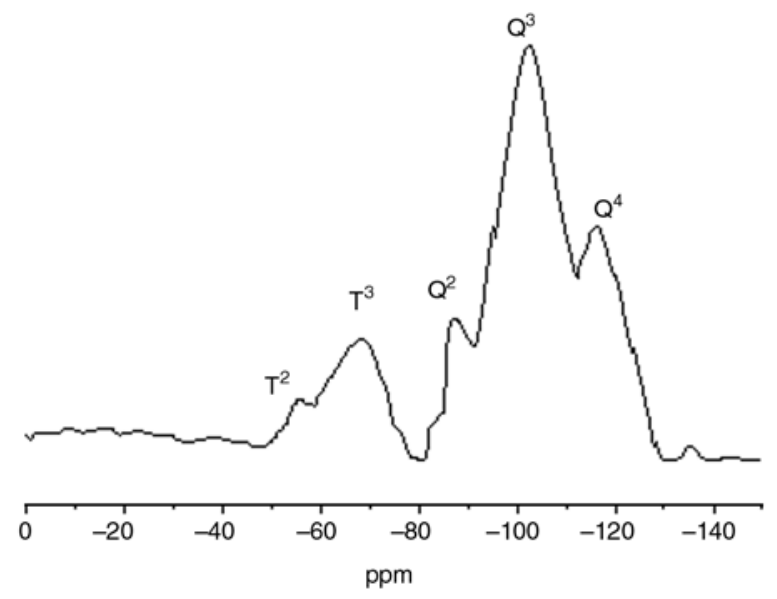

Figure 3. Solid-state ${ }^{29} \mathrm{Si}$ NMR spectrum of hybrid (Z3)

form carboxylic acid and amide. However the TEOS and triethoxy-silicon group of APTES formed inorganic network by hydrolysis and condensation, which could be demonstrated by the absorption, peaks of $\mathrm{Si}-\mathrm{O}-\mathrm{Si}$ asymmetric stretching (1100 to $\left.1050 \mathrm{~cm}^{-1}\right)$ and symmetric stretching $\left(728 \mathrm{~cm}^{-1}\right)$.

Figure 3 displays the solid-state ${ }^{29} \mathrm{Si} \mathrm{NMR}$ spectra of the hybrid nanocomposite (Z3). The condensed siloxane species originating from TEOS, the silicon atoms through mono-, di-, tri-, and tetra-substituted siloxane bonds were designated as $\mathrm{Q}^{1}, \mathrm{Q}^{2}, \mathrm{Q}^{3}$, and $\mathrm{Q}^{4}$, respectively. The various $\mathrm{Q}^{\mathrm{S}}$ were defined in Figure 4.

The 3-aminopropyltriethoxysilane, APTES, similarly with mono-, di-, tri-, tetra-substituted siloxane bonds were designated as $\mathrm{T}^{1}, \mathrm{~T}^{2}, \mathrm{~T}^{3}$, respectively. The various $\mathrm{T}^{\mathrm{S}}$ are defined in Figure 5.

The chemical shifts from the ${ }^{29} \mathrm{Si}$ NMR spectra of $\mathrm{Q}^{2}, \mathrm{Q}^{3}$, and $\mathrm{Q}^{4}$ were $-87,-102,-116 \mathrm{ppm}$, respectively, and were similar to those reported in the lit- 
<smiles>CO[Si](O)(O)O[Si](O)(O[Si](O)(O)O[Si]([14CH3])(O)O)O[Si](O[Si](O)(O)O)(O[Si](O)(O)OC)O[Si](O)(O)OC</smiles>

Figure 4. Abbreviations used for Si atoms attached to four oxygen atoms in various structural positions

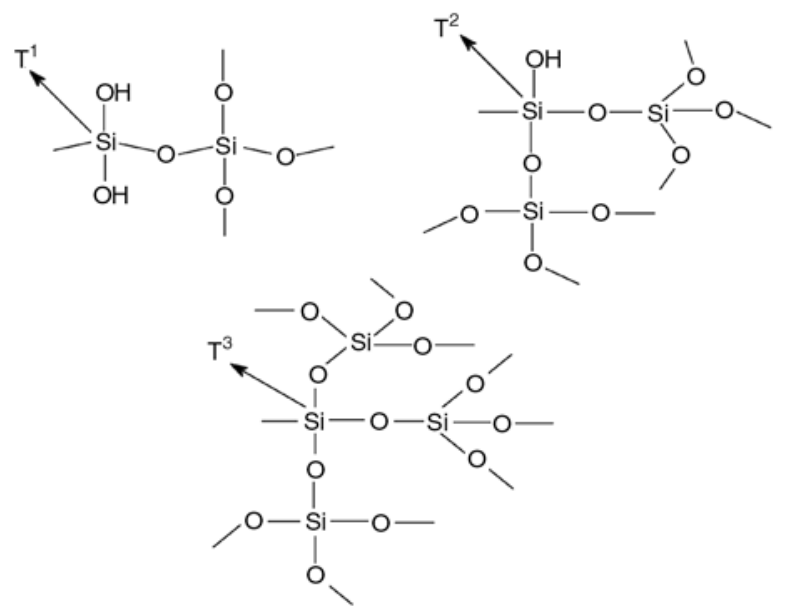

Figure 5. Abbreviations used for $\mathrm{Si}$ atoms attached to three oxygen atoms in various structural positions

erature [17]. The chemical shifts of $\mathrm{T}^{2}$ and $\mathrm{T}^{3}$ were -54 and $-68 \mathrm{ppm}$, respectively, and also in good agreement with the literature values [18]. Results revealed that $\mathrm{Q}^{3}, \mathrm{Q}^{4}$ and $\mathrm{T}^{3}$ were the major microstructures forming a network structure.

\subsection{Determination of sol fraction}

As is well known, good solvent will extract the part, which doesn't cross link with chemical bond. After the synthetic hybrid materials were extracted

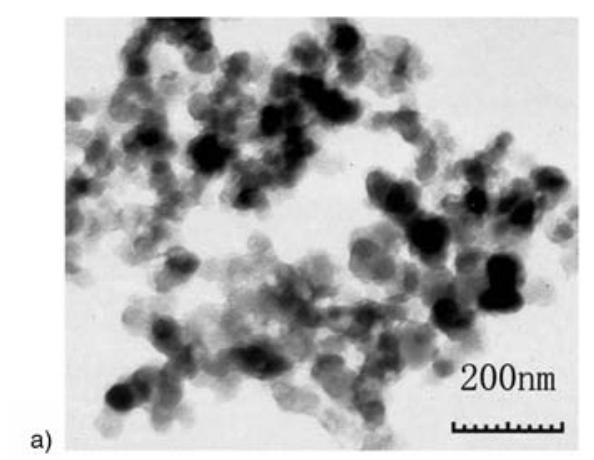

with acetone, the extraction sol is the copolymer, which doesn't combine to inorganic network with the covalent bond. The results of extraction experiments were $5.8 \%(\mathrm{Z} 1), 5.5 \%(\mathrm{Z} 2), 5.1 \%(\mathrm{Z} 3)$ and $4.9 \%(\mathrm{Z} 4)$ and $4.7 \%(\mathrm{Z} 5)$ respectively. This shows combination with chemical bond between organic and inorganic parts. Coupling agent APTES could integrate between the organic unit of the copolymer and inorganic network with covalent bond and restrain the extracted hybrid materials.

\subsection{Microstructure analysis}

Figure 6 shows the TEM pictures of Z2 and Z5 respectively. The silica particle size was about 50-70 nm.

\subsection{Thermal analysis}

The results of differential scanning calorimetry (DSC) and thermal gravimetric analysis (TGA) are shown by Figures 7, 8 and Table 2. The glass transition temperatures $\left(T_{g}\right)$ and the thermal degradation temperatures $\left(T_{d}\right)$ of the hybrids increased with the increase of APTES content. This is due to the fact that the plasticizing trimethoxysilyl groups have transformed to silica network during the solgel process. The large-scale cooperative movement

Table2. Thermal properties of hybrid materials

\begin{tabular}{|c|c|c|}
\hline Hybrid material & $\mathbf{T}_{\mathbf{g}}\left[{ }^{\circ} \mathbf{C}\right]^{\mathbf{1}}$ & $\mathbf{T}_{\mathbf{d}}\left[{ }^{\circ} \mathbf{C}\right]^{\mathbf{2}}$ \\
\hline Z1 & 122 & 292 \\
\hline Z2 & 134 & 298 \\
\hline Z3 & 148 & 303 \\
\hline Z4 & 152 & 309 \\
\hline Z5 & 160 & 313 \\
\hline
\end{tabular}

${ }^{1}$ The glass transition temperature $\left(T_{g}\right)$ was obtained from DSC curves

${ }^{2}$ The thermal degradation temperatures $\left(T_{d}\right)$ were defined as weight loss of TGA thermogram at $5 \mathrm{wt} \%$

b)

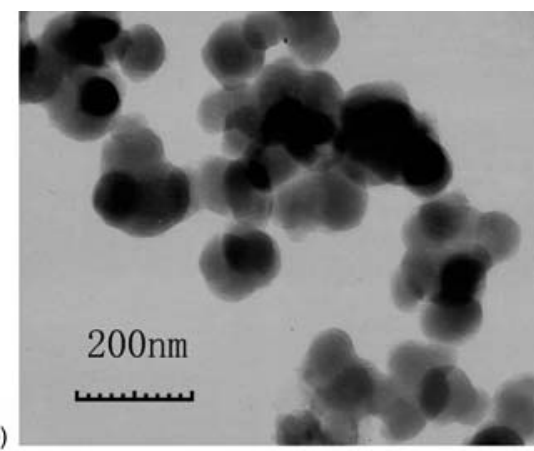

Figure 6. TEM pictures of poly (St-MAn-APTES)/SiO 2 for $\mathrm{Z} 2$ (a) and Z5 (b) 


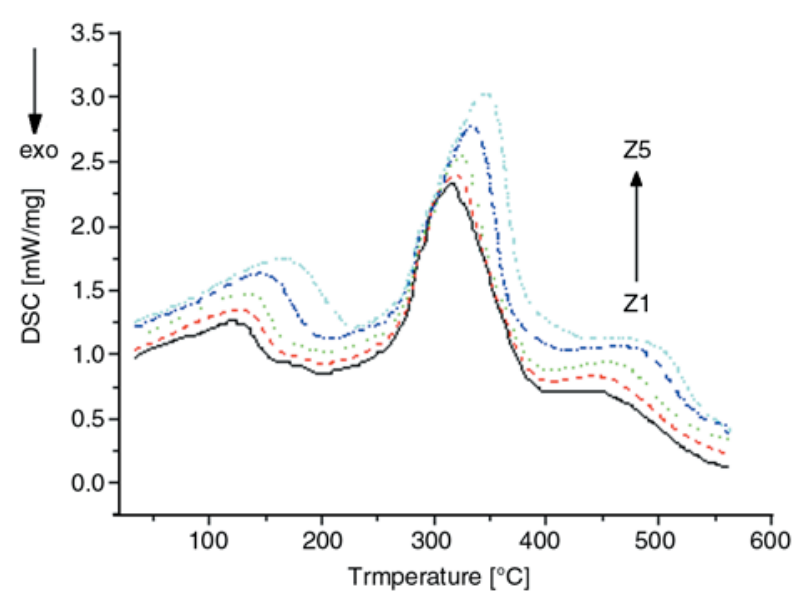

Figure 7. DSC curves of hybrid materials

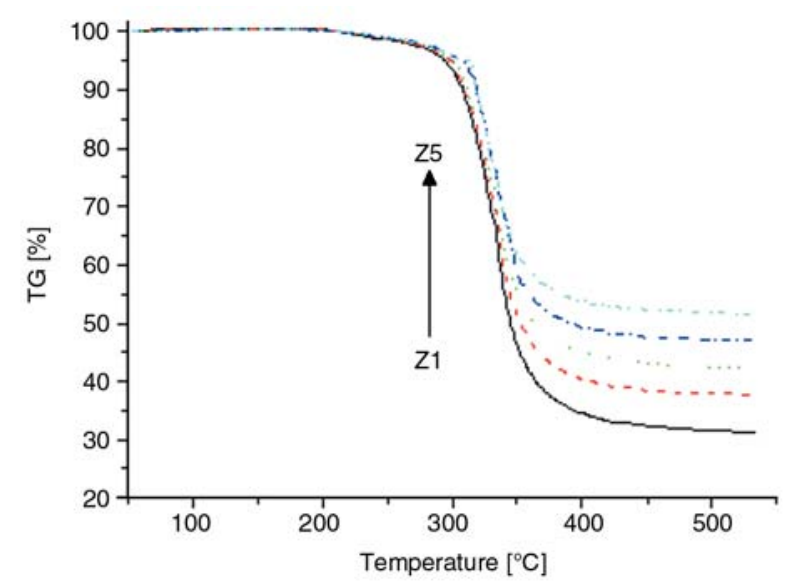

Figure 8. TGA curves of hybrid materials

of the polymer chain segments (i. e., glass transition) was highly restricted by the cross linking points that are generated from the formation of covalent bonds between the polymer chains and the silica network as well as by steric hindrance of the rigid silica (hydrolysis and condensation of TEOS) framework.

\section{Conclusions}

Different $\mathrm{SiO}_{2}$ content hybrids were synthesized by the sol-gel process. FT-IR and ${ }^{29} \mathrm{Si}$ NMR were used to characterize the structure of the hybrids. The results show that $\mathrm{Q}^{3}, \mathrm{Q}^{4}$ and $\mathrm{T}^{3}$ are the major microstructures forming the network structure. The $\mathrm{SiO}_{2}$ structures in TEOS based hybrid systems were completely condensed. So these hybrid materials have network structure and inorganic phases have a small size. The hybrids were nanocomposites. Covalent bonding between the organic and inorganic components enhanced miscibility between the silica and the copolymer, which was further confirmed by TEM and the determination of sol content. Because the amino-group of coupling agent APTES breaks maleic anhydride of copolymer to form carboxylic acid and amide, the hybrids have new nanosystems with extremely good heat resistance, resulting from

\section{Acknowledgements}

This work was financially supported by the Jiangsu Planned Projects for Postdoctoral Research Funds (0602037B), the Natural Science of Jiangsu Education (05KJB150016) and the fund of Jiangsu University (06JDG015 and 06JDG076).

\section{References}

[1] Brennan A. B., Wilkes G. L.: Structure-property behavior of sol-gel derived hybrid materials: effect of a polymeric acid catalyst. Polymer, 32, 733-739 (1991).

[2] Chiang C-L., Ma C-C. M.: Synthesis, characterization and thermal properties of novel epoxy containing silicon and phosphorus nanocomposites by sol-gel method. European Polymer Journal, 38, 2219-2224 (2002).

[3] Hsiue G-H., Kuo W-J., Huang Y-P., Jeng R-J.: Microstructural and morphological characteristics of $\mathrm{PS}_{-} \mathrm{SiO}_{2}$ nanocomposites. Polymer, 41, 2813-2825 (2000).

[4] Hsu Y. G., Lin K. H., Chiang I. L.: Organic-inorganic hybrid materials based on the incorporation of nanoparticles of polysilicic acid with organic polymers. 1 . Properties of the hybrids prepared through the combination of hydroxyl-containing linear polyester and polysilicic acid. Materials Science Engineering: B, 87, 31-39 (2001).

[5] Ershad-Langroudi A., Mai C., Vigier G., Vassoille R.: Hydrophobic hybrid inorganic-organic thin film prepared by sol-gel process for glass protection and strengthening applications. Journal of Applied Polymer Science, 65, 2387-2393 (1997).

[6] Philipp G., Schmidt H.: New materials for contact lenses prepared from $\mathrm{Si}$ - and $\mathrm{Ti}$-alkoxides by the solgel process. Journal of Non-Crystalline Solids, 63, 283-292 (1984).

[7] Chen W-C., Lee S-J., Lee L-H., Lin J-L.: Synthesis and characterization of trialkoxysilane-capped poly (methyl methacrylate)-titania hybrid optical thin films. Journal of Materials Chemistry, 9, 2999-3003 (1999).

[8] Kagan C. R., Mitzi D. B., Dimitrakopoulos C. D.: Organic-inorganic hybrid materials as semi conducting channels in thin-film field-effect transistors. Science, 286, 945-947 (1999).

[9] Huynh W. U., Dittmer J. J., Alivisatos A. P.: Hybrid nanorod-polymer solar cells. Science, 295, 2425-2427 (2002). 
[10] Huang W. Y., Ho S. W., Kwei T. K., Okamoto Y.: Photoluminescence behavior of poly (quinoline) $\mathrm{s}$ in silica glasses via the sol-gel process. Applied Physics Letter, 80, 1162-1164 (2002).

[11] Yoshida M., Prasad P. N.: Sol-gel-processed $\mathrm{SiO}_{2} / \mathrm{TiO}_{2} /$ poly (vinyl pyrrolidone) composite materials for optical waveguides. Chemistry of Materials, $\mathbf{8}$, 235-241 (1996).

[12] Biteau J., Chaput F., Lahlil K., Boilot J. P., Tsivgoulis G. M., Lehn J-M., Darracq B., Marois C., Lévy Y.: Large and stable refractive index change in photochromic hybrid materials. Chemistry of Materials, 10, 1945-1950 (1998).

[13] Miller R. D., Michl J.: Polysilane high polymers. Chemical Reviews, 89, 1359-1410 (1989).

[14] Wei Y., Yang D. C., Tang L. G.: Synthesis, characterization, and properties of new polystyrene- $\mathrm{SiO}_{2}$ hybrid sol-gel materials. Journal of Materials Research, 8, 1143- 1152 (1993).
[15] Coltrain B. K., Landry C. J. T., O'Reilly J. M., Chamberlain A. M., Rakes G. A., Sedita J. S., Kelts L. W., Landry M. R., Long V. K.: Role of trialkoxysilane functionalization in the preparation of organic-inorganic composites. Chemistry of Materials, 5, 14451455 (1993).

[16] Qiu F-X., Zhou Y-M., Liu J-Z.: The synthesis and characteristic study of 6FDA-6FHP-NLO polyimide/ $\mathrm{SiO}_{2}$ nanohybrid materials. European Polymer Journal, 40, 713-720 (2004).

[17] Qiu F. X., Jiang Y., Zhou Y. M., Liu J. Z.: Synthesis, characterization and thermal properties of novel PMDA-PAPD/silica hybrid network polymers. Silicon Chemistry, 3, 65-73 (2006).

[18] Joseph R., Zhang Z., Ford W. T.: Structure and dynamics of a colloidal silica-poly (methacrylate) composite by ${ }^{13} \mathrm{C}$ and ${ }^{29} \mathrm{Si}$ MAS NMR spectroscopy. Macromolecules, 29, 1305-1312 (1996). 